\title{
Development of a Method for Calculating the Working Blade Stress Profile of the Aviation Gas Turbine Engine for Student Training
}

\author{
Ilmārs Ozoliṇšs ${ }^{1}$, Ėriks Ozoliṇš ${ }^{2}$, Valērija Fedotova ${ }^{3}$ \\ ${ }^{1,2}$ Institute of Aeronautics, Faculty of Mechanical Engineering, Transport and Aeronautics, \\ Riga Technical University, Riga, Latvia \\ ${ }_{3}^{3}$ JSC Air Baltic Corporation, Riga, Latvia
}

\begin{abstract}
The paper presents a method of calculation gas turbine engine compressor or lowpressure turbine working blade profile for student training. This method of calculation was prepared for working blades with and without shroud shelves. This method provides a calculation technique to reduce the load on blade root part and the determination of blade profile stress distribution and the comparison before and after reduction of load.
\end{abstract}

Keywords - Bending stress, blade profile, shroud shelf, working blade.

\section{INTRODUCTION}

One of the most loaded and, as follows, the most expensive parts in civil aviation is the engine. This is due to heavy working conditions that are subjected to various engine parts and elements. During design and manufacturing phase of an engine, a special attention is paid exactly to engine rotors, as they additionally absorb significant centrifugal forces.

The manuscript considers the method of calculation the working blade, that can provide an in-depth understanding for aviation specialty students of details calculation of a complex form, the nuances and issues, and simply for those who are interested in calculation of such algorithms. Nowadays, calculations of this kind of details are done using computer modelling techniques, but during the training process, such type of modelling is not always able to provide clear calculation details. Therefore, a classical calculation method was offered, which was accomplished in the Microsoft Excel program. The proposed calculation suits the best for the calculation of working blades of compressors or low-pressure turbines, as they do not contain internal cooling channels. Here is to note that for the student training the high accuracy of calculations that computer modelling can provide is not so important, but it is important that clear picture of the whole calculation process that lead to understanding of the concept logic.

This is achieved mainly due to the fact that, unlike computer modelling, the calculation algorithm is more transparent in the classical computer calculation. Clear is the connection link between the output data, the wide range of intermediate and final results, which provide additional possibilities for the convenience of an in-depth analysis of the calculations. This allows to implement further improvements, thus increasing the accuracy of the calculation.

The main accent in this work was placed directly on calculation of the working blade profile and the choice of its position on the impeller that would ensure a minimal impact of the static load on the blade profile elements. In other words, how a blade has to be mounted on a disc to minimize the stresses in the most loaded are of the blade. The calculation for a blade with shroud shelf was also implemented, which is typical for low-pressure turbine working blades. There was a possibility to compare the results of calculations for the blades with and without shroud shelf. The analysis of the results can be expanded by changing blades materials and by varying engine operating modes. 


\section{Blade Profile Calculation}

To calculate the blade profile the following assumptions are made [1]-[4]:

- blade is rigid;

- blade is cantilevered;

- blade mounting on a disc is rigid;

- stresses do not exceed the elastic limit;

- thermal stresses are not taken into consideration;

- torsion tangential stresses are not taken into consideration.

Considering the abovementioned assumptions, tensile and bending stresses from the centrifugal forces and bending stresses from the gas forces are taken into account. In this calculation the determinant forces that influence the working blade are emphasised. The abovementioned assumptions allow to avoid the complex and labour-intensive calculations.

The initial data required for the accomplishment of the calculation corresponds to the classical calculation. The initial data are the diameter and the rotation velocity of the rotor, material density, geometrical parameters of the blade and gas dynamic values of the stage. Table I shows a part of calculation results with the initial data, as well as the intermediate results for the determination of which the already known calculation method [1]-[4] was used with the small changes. The detailed description of the mentioned and analogical calculations which can be found in the literature [1][15], is not presented in this article and is limited only to final results. For more comfortable and transparent calculation of the working blade profile the method was divided into several stages. Increasing the number of stages, it is possible to increase the accuracy of the calculations.

In the given numerical example, the blade without shroud shelf was chosen and its profile is divided into nine cross sections (eight slices accordingly) (Fig. 1a). Here $1^{\text {st }}$ section is the upper end of the blade. In the first column of the Table I (Section) the sections of the blade are shown. If the values are referred to the slice of the blade (e.g. weight of a slice $m_{\text {slice, }}$, centrifugal forces of the slice $P_{c f \text { slice }}$ ), then the values of the given slice are written near the lower section of the slice (Fig. 3). It means that in the table the mass of the first slice is written in the row of the $2^{\text {nd }}$ section, and zero value is written in the first section because there are no slices of the blade above this section.

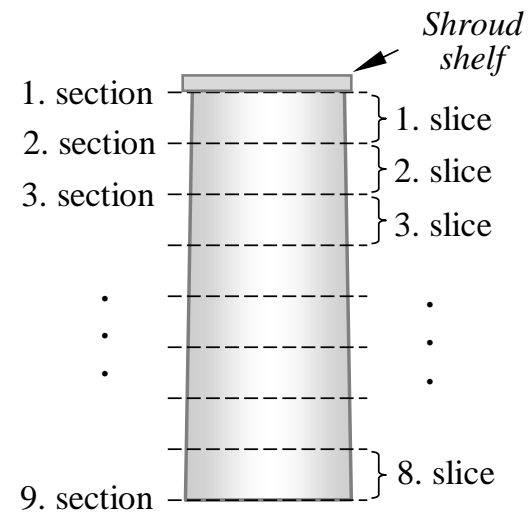

a)

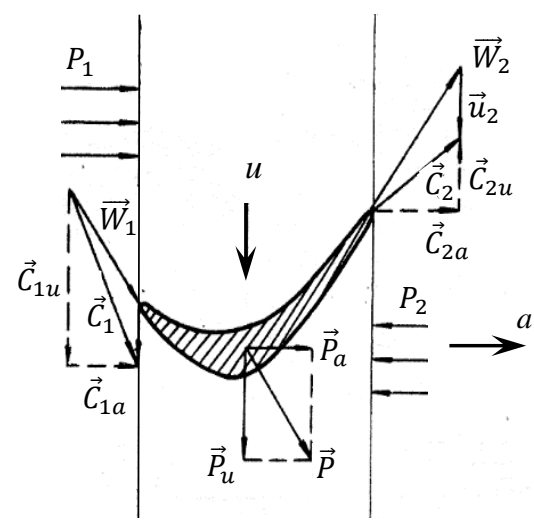

b)

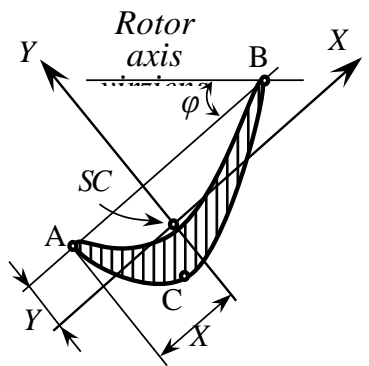

c)

Fig. 1. Working blades division into sections and slices $(a)$, velocity triangles in front and behind turbine blade $(b)$, three points of blade profile $(c)$.

Where $r$ - radius in the given section; $F$ - profile cross-section area in the given section; $S C_{\text {slice }}-$ centre of gravity of the given slice; $P_{c f}$ slice - centrifugal force of the given slice; $m_{\text {slice }}$ - mass of the given slice; $S C_{\Sigma}$ - centre of gravity of the slice from the end of the blade to the given (or necessary) section; $P_{c f \Sigma}$ - centrifugal force of the slice from the end of the blade to the necessary section; $\sigma_{c f}-$ tensile stress in the given section. 


\section{TABLE I}

CAlculation Results EXAMPLE

\begin{tabular}{|c|c|c|c|c|c|c|c|c|}
\hline Section & $r, \mathrm{~m}$ & $F, \mathrm{~m}^{2}$ & $S C_{\text {slice }}, \mathrm{m}$ & $P_{c f \text { slice }}, \mathrm{N}$ & 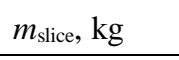 & $S C_{\Sigma}, \mathrm{m}$ & $P_{c f \Sigma}, \mathrm{N}$ & $\sigma_{c f}, \mathrm{MPa}$ \\
\hline 1 & 0.336 & 4.4995E-05 & 0 & 0 & 0 & 0 & 0 & 0 \\
\hline 2 & 0.3277 & $5.187 \mathrm{E}-05$ & 0.0040518 & 2038.56 & 0.00321 & 0.331751 & 2038.56 & 39.30 \\
\hline 3 & 0.3194 & $5.9995 \mathrm{E}-05$ & 0.0040495 & 2295.33 & 0.00371 & 0.327302 & 4333.90 & 72.23 \\
\hline 4 & 0.3111 & $6.937 \mathrm{E}-05$ & 0.0040497 & 2586.30 & 0.00429 & 0.322652 & 6920.20 & 99.75 \\
\hline 5 & 0.3028 & 7.9995E-05 & 0.0040516 & 2907.51 & 0.00495 & 0.317810 & 9827.72 & 122.85 \\
\hline 6 & 0.2945 & $9.187 \mathrm{E}-05$ & 0.0040544 & 3255.03 & 0.00570 & 0.312791 & 13082.76 & 142.40 \\
\hline 7 & 0.2862 & 0.000105 & 0.0040577 & 3624.91 & 0.00653 & 0.307610 & 16707.67 & 159.12 \\
\hline 8 & 0.2779 & 0.00011937 & 0.0040613 & 4013.19 & 0.00744 & 0.302284 & 20720.86 & 173.58 \\
\hline 9 & 0.2696 & 0.000135 & 0.0040650 & 4415.92 & 0.00844 & 0.296831 & 25136.78 & 186.20 \\
\hline
\end{tabular}

Similarly also the other values that are necessary for the calculation (not shown in this article) and can be determined by using classic calculation methods are inserted in the table: $C_{1 a}$-gas flow axial (in the direction of rotor axis) velocity in front of the blade (Fig. 1b.); $C_{2 a}$ - gas flow axial velocity behind the blade; $C_{1 u}, C_{2 u}$ - gas flow peripherical velocity accordingly in front of the blade (in the direction of rotor circumference) and behind the blade; $p_{1}{ }^{*}, p_{2}{ }^{*}$ - total pressure accordingly in front and behind the blade; $P_{a}$ - axial direction forces, that impacts each slice of the blade; $M_{u}-$ moments of axial forces in respective sections; $P_{u}$ - circumferential direction forces that impacts each slice of the blade; $M_{a}$ - moments of circumferential direction forces in respective sections; $\varphi$ - angle of torsion of the blade (in the given section this angle is between rotor axis and the profile chord) (Fig. 1c); $M_{x}$ - bending moment in the given section in relation to the main central inertial axis $x$ of the section (in the given section this axis passes through profile centre of mass and is perpendicular to the profile chord); $M_{y}$ - bending moment in the given section in relation to the main central inertial axis $y$ of the section (in the given section this axis passes through profile centre of mass and is practically parallel to the profile chord); $I_{x}$ - polar moment of inertia of the given slice in relation to axis $x ; I_{y}$ - polar moment of inertia of the given slice in relation to axis $y . Y_{\mathrm{A}}, Y_{\mathrm{B}}$ and $Y_{\mathrm{C}}$-distance (or coordinate) between axis $y$ and the profile dangerous point accordingly $\mathrm{A}, \mathrm{B}$ and $\mathrm{C}$ in the given section (Fig. 3.); $X_{\mathrm{A}}, X_{\mathrm{B}}$ and $X_{\mathrm{C}}$ - distance (or coordinate) between axis $x$ and the profile dangerous point accordingly $\mathrm{A}, \mathrm{B}$ and $\mathrm{C}$ in the given section; $\sigma_{\mathrm{A}}, \sigma_{\mathrm{B}}$ and $\sigma_{\mathrm{C}}-$ stress created by gas forces bending moments in the profile point $\mathrm{A}, \mathrm{B}$ and $\mathrm{C}$ accordingly (in the given section); $\sigma_{\text {sum A }}, \sigma_{\text {sum B }}$ and $\sigma_{\text {sum C }}-$ total stresses in profile points $\mathrm{A}, \mathrm{B}$ and $\mathrm{C}$ accordingly created by bending moments and centrifugal forces. Bending and total stress values are shown in Table II. Using the values from this table the bending stress and the total stress dependence can be drawn as chart showing blade's each section points A, B and C (Fig. 2).

\section{TABLE II}

BENDING AND TOTAL STRESSES

\begin{tabular}{|l|r|r|r|r|r|r|}
\hline Section & $\sigma_{\mathrm{A}}, \mathrm{MPa}$ & $\sigma_{\mathrm{B}}, \mathrm{MPa}$ & $\sigma_{\mathrm{C}}, \mathrm{MPa}$ & $\sigma_{\text {sum A }}, \mathrm{MPa}$ & $\sigma_{\text {sum B }}, \mathrm{MPa}$ & $\sigma_{\text {sum C }}, \mathrm{MPa}$ \\
\hline 1 & 0 & 0 & 0 & 0 & 0 & 0 \\
2 & 4.89 & 3.26 & -3.10 & 44.194 & 42.560 & 36.199 \\
3 & 14.53 & 9.18 & -10.99 & 86.772 & 81.414 & 61.245 \\
4 & 29.08 & 17.47 & -24.69 & 128.843 & 117.225 & 75.058 \\
5 & 46.41 & 26.47 & -42.52 & 169.264 & 149.329 & 80.329 \\
6 & 65.59 & 35.36 & -63.00 & 207.998 & 177.765 & 79.398 \\
7 & 86.10 & 43.47 & -84.79 & 245.227 & 202.598 & 74.335 \\
8 & 107.53 & 50.15 & -106.62 & 281.119 & 223.737 & 66.960 \\
9 & 129.55 & 54.65 & -127.37 & 315.762 & 240.859 & 58.833 \\
\hline
\end{tabular}


From Fig. 4 it is obvious, that the most loaded part of the blade is the base slice. The next step is to reduce the loading of bending stresses on the working blade i.e. the selection of its position on the impeller, that would ensure a minimal static load influence on the blade profile elements. In practice, the blade is simply skewed in the direction of gas flow both in rotor axis and a circumferential direction. Skewing of a blade means that the values of gas forces and centrifugal forces and their moments change, but in literary sources does not give a detailed explanation of how to account for these changes.

In this context a method of determination of skewness value is presented. The method of calculation of the skewness value and the stresses related is provided below in details.

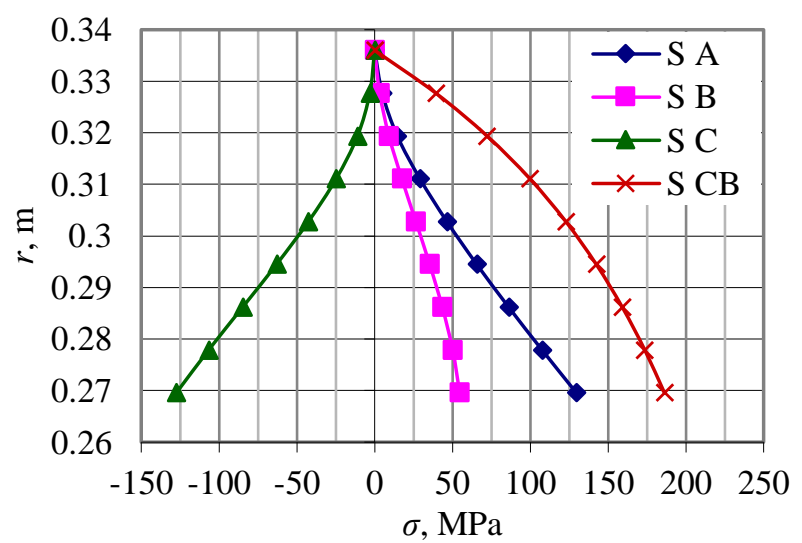

a)

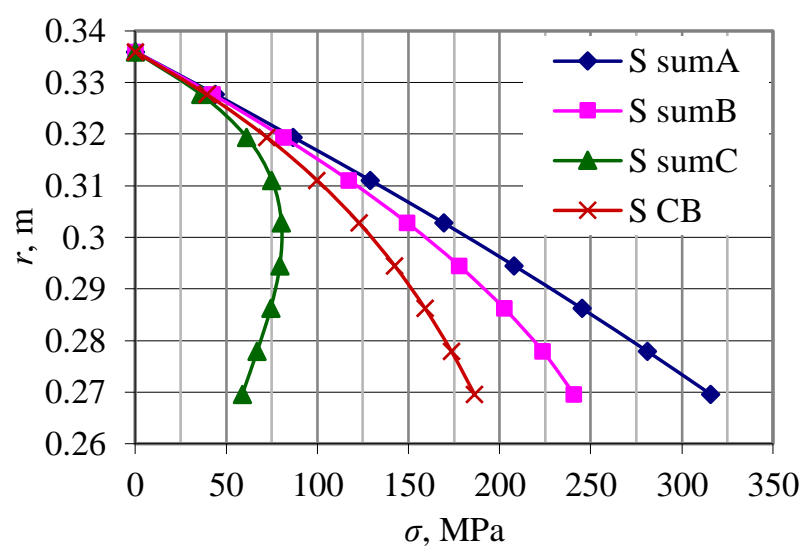

b)

Fig. 2. Bending $(a)$ and total $(b)$ stresses as well as the tensile stress $\left(\sigma_{c f}\right)$ distribution along the blade length before stress reduction where $\sigma_{\mathrm{A}}, \sigma_{\mathrm{B}}$ and $\sigma_{\mathrm{C}},-$ bending stresses in profile points $\mathrm{A}, \mathrm{B}$ and $\mathrm{C}$ accordingly; $\sigma_{\text {sumA }}, \sigma_{\text {sumB }}$ and $\sigma_{\text {sumC }}-$ bending and circumferential stresses in profile points $\mathrm{A}, \mathrm{B}$ and $\mathrm{C}$ accordingly; $\sigma_{c f}$ - circumferential force created stresses.

\section{BLADE LOAD REDUCTION CALCULATION}

To make the explanation of the essence of calculation easier we will recline on a simplified demonstration example where it is assumed that the blade is divided in 4 slices, or 5 sections accordingly (Fig. 3).

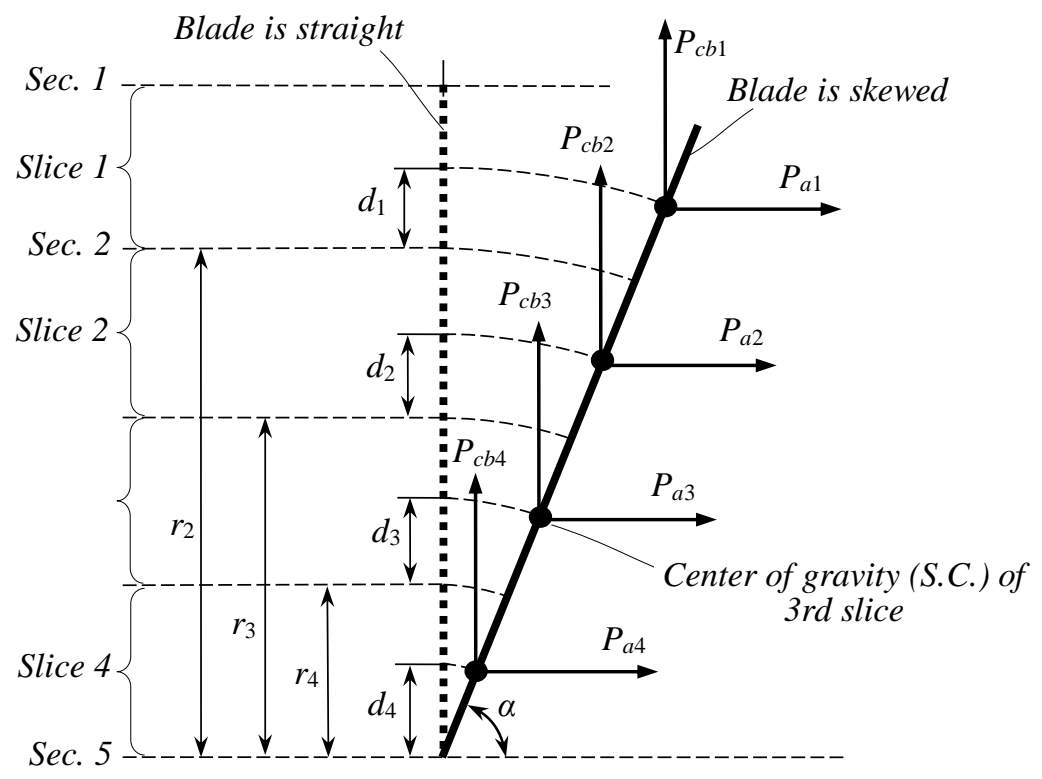

Fig.3. Scheme of blade in straight and skewed position in rotor axis direction.

But the numerical results will be displayed from 9 section calculation version. The aim of the task is to define the skew angle $\alpha$ (it will be equal in all sections) that could reduce loading of the most 
loaded part - the base (demonstration example $5^{\text {th }}$ section). Offered below is a total gas forces and centrifugal forces created moment equation:

$$
\begin{gathered}
P_{a 1} \cdot\left(r_{2}+d_{1}\right) \sin \alpha+P_{a 2} \cdot\left(r_{3}+d_{2}\right) \sin \alpha+P_{a 3} \cdot\left(r_{4}+d_{3}\right) \sin \alpha+ \\
+P_{a 4} \cdot d_{4} \sin \alpha=P_{c b 1} \cdot\left(r_{2}+d_{1}\right) \cos \alpha+P_{c b 2} \cdot\left(r_{3}+d_{2}\right) \cos \alpha+ \\
+P_{c b 3} \cdot\left(r_{4}+d_{3}\right) \cos \alpha+P_{c b 4} \cdot d_{4} \cos \alpha
\end{gathered}
$$

After putting outside of the brackets $\sin \alpha$ on the left side and $\cos \alpha$ on the right side of the equation, moving $\cos \alpha$ to the left side and gas forces created moments to the right side we obtain:

$$
\frac{\sin \alpha}{\cos \alpha}=\left(\frac{P_{c b 1} \cdot\left(r_{2}+d_{1}\right)+P_{c b 2} \cdot\left(r_{3}+d_{2}\right)+}{P_{a 1} \cdot\left(r_{2}+d_{1}\right)+P_{a 2} \cdot\left(r_{3}+d_{2}\right)+} \frac{P_{c b 3} \cdot\left(r_{4}+d_{3}\right)+P_{c b 4} \cdot d_{4}}{P_{a 3} \cdot\left(r_{4}+d_{3}\right)+P_{a 4} \cdot d_{4}}\right)
$$

since

$$
\tan \alpha=\frac{\sin \alpha}{\cos \alpha}
$$

then

$$
\tan \alpha=\left(\frac{P_{c b 1} \cdot\left(r_{2}+d_{1}\right)+P_{c b 2} \cdot\left(r_{3}+d_{2}\right)+}{P_{a 1} \cdot\left(r_{2}+d_{1}\right)+P_{a 2} \cdot\left(r_{3}+d_{2}\right)+} \frac{P_{c b 3} \cdot\left(r_{4}+d_{3}\right)+P_{c b 4} \cdot d_{4}}{P_{a 3} \cdot\left(r_{4}+d_{3}\right)+P_{a 4} \cdot d_{4}}\right)
$$

From here the blade skew angle $\alpha$ is found:

$$
\alpha=\tan \left(\frac{P_{c b 1} \cdot\left(r_{2}+d_{1}\right)+P_{c b 2} \cdot\left(r_{3}+d_{2}\right)+P_{c b 3} \cdot\left(r_{4}+d_{3}\right)+P_{c b 4} \cdot d_{4}}{P_{a 1} \cdot\left(r_{2}+d_{1}\right)+P_{a 2} \cdot\left(r_{3}+d_{2}\right)+P_{a 3} \cdot\left(r_{4}+d_{3}\right)+P_{a 4} \cdot d_{4}}\right)
$$

Since on the right side of the equation (5) all values are known the value of the angle simply has to be calculated. The calculation in the circumferential direction is identical. In the numerical example $\alpha$, as well as $\cos \alpha, \sin \alpha$ the results in axial and circumferential directions are shown in Table III.

TABLE III

BLADE SKEW ANGLES

\begin{tabular}{|l|l|l|l|l|l|}
\hline \multicolumn{2}{|l|}{ Rotor axial direction } & \multicolumn{3}{|c|}{ Rotor circumferential direction } \\
\hline$\alpha,{ }^{\circ}$ & $\cos \alpha$ & $\sin \alpha$ & $\alpha,{ }^{\circ}$ & $\cos \alpha$ & $\sin \alpha$ \\
\hline 84.5317 & 0.0952 & 0.9954 & 85.6813 & 0.0753 & 0.9971 \\
\hline
\end{tabular}

Here $\cos \alpha=\cos (\alpha \cdot \pi / 180)$ and $\sin \alpha=\sin (\alpha \cdot \pi / 180)$.

In this particular case the reduction of slice centrifugal forces, that is brought by reduction of radius, which in its turn is brought by blade skewing, is not taken into consideration. By analogy a potential gas forces reduction, which is created by slice area where gas flow components collide reduction is not taken into consideration. It can be marked that the inobservance of changes in both forces mentioned does not lead to a remarkable mistake, because firstly these changes are minor, and, secondly precisely the simplification of both mentioned forces tends to compensate each other. Except that in the current calculation the task is to completely relieve the $9^{\text {th }}$ slice from bending stresses, but while making calculation it is important to consider that in cruise level centrifugal and gas forces distribution will change because of the change of the air flow parameters and engine work mode (rotation). This is the reason why the load shedding coefficient $\xi$ which forces these changes has to be introduced ensuring maximum load reduction precisely during flight cruise level. But to simplify of the given calculation this coefficient is assumed $\xi=1$ (or the calculation is made precisely for the cruise level).

Further to verify that the calculation is correct, a check can be performed. For this purpose, the $\cos \alpha$ and $\sin \alpha$ values are needed. During the test calculation it has to be verified that $5^{\text {th }}$ section (root section) gas forces and centrifugal forces moments are equal.

$$
\sum_{i=1}^{5} M_{c b i}=\sum_{i=1}^{5} M_{a i}
$$


By replacing moments with the forces and shoulders product the coherence (1) is received. The Table IV shows that in the root section $\left(9^{\text {th }}\right.$ section) the results coincide, what indicates, that there is no error. In addition, in order to determine the stress values not only root section, but also in other blade sections, the values of the moments have to be calculated in all sections (see Table IV). By analogy the calculation can be made in a circumferential direction. In the given article this procedure is omitted and limited by the presentation of the results (see Table IV).

TABLE IV

BENDING MOMENTS VALUES

\begin{tabular}{|l|l|l|l|l|}
\hline \multirow{2}{*}{ Section } & \multicolumn{2}{l|}{ Rotor axial direction } & \multicolumn{2}{l|}{ Rotor circumferential direction } \\
\cline { 2 - 5 } & $\mathrm{Mu}, \mathrm{Nm}$ & $\mathrm{Mcf}, \mathrm{Nm}$ & $\mathrm{Ma}, \mathrm{Nm}$ & Mcf, Nm \\
\hline 1 & 0 & 0 & 0 & 0 \\
2 & 1.095 & 0.787 & 0.759 & 0.622 \\
3 & 4.407 & 3.285 & 3.097 & 2.596 \\
4 & 9.885 & 7.711 & 7.069 & 6.094 \\
5 & 17.477 & 14.307 & 12.737 & 11.306 \\
6 & 27.132 & 23.338 & 20.162 & 18.442 \\
7 & 38.798 & 35.088 & 29.415 & 27.727 \\
8 & 52.423 & 49.855 & 40.568 & 39.397 \\
9 & 67.955 & 67.955 & 53.699 & 53.699 \\
\hline
\end{tabular}

The final stage of the calculation is linked with stress values calculation for the blade with already reduced pressure. In addition, the stress values will be the total values including forces in both rotor axis and circumferential direction. It is clear, that in blade root section the stress must be equal to zero, but we are also interested in stress level in other blade sections. For this purpose, firstly, bending moments $M_{x}$ and $M_{y}$ have to be recalculated in relation to main section's axes $x$ and accordingly $y$. Here unlike the calculation that was performed before stress reduction (see Table I) the difference of bending moments created by gas forces and centrifugal forces have to be used. Results are shown in Table V.

$$
\begin{aligned}
& M_{x}=\left(M_{a}-M_{c b}\right) \cdot \cos \varphi+\left(M_{u}-M_{c b}\right) \cdot \sin \varphi \\
& M_{y}=\left(M_{a}-M_{c b}\right) \cdot \sin \varphi+\left(M_{u}-M_{c b}\right) \cdot \cos \varphi
\end{aligned}
$$

Then bending stresses are recalculated:

$$
\begin{aligned}
& \sigma_{A}=\left(\frac{M_{x}}{I_{x}} \cdot Y_{A}+\frac{M_{y}}{I_{y}} \cdot X_{A}\right) \cdot 10^{-6} \\
& \sigma_{B}=\left(\frac{M_{x}}{I_{x}} \cdot Y_{B}+\frac{M_{y}}{I_{y}} \cdot X_{B}\right) \cdot 10^{-6} \\
& \sigma_{C}=\left(\frac{M_{x}}{I_{x}} \cdot Y_{C}+\frac{M_{y}}{I_{y}} \cdot X_{C}\right) \cdot 10^{-6}
\end{aligned}
$$


TABLE V

BENDING MOMENTS AND STRESSES VALUES

\begin{tabular}{|c|c|c|c|c|c|c|c|c|}
\hline Section & $M_{x}, \mathrm{Nm}$ & $M_{y}, \mathrm{Nm}$ & $\sigma_{\mathrm{A}}, \mathrm{MPa}$ & $\sigma_{\mathrm{B}}, \mathrm{MPa}$ & $\sigma_{\mathrm{C}}, \mathrm{MPa}$ & $\begin{array}{l}\sigma_{\text {sum Am }}, \\
\mathrm{MPa}\end{array}$ & $\begin{array}{l}\sigma_{\text {sum B }} \\
\mathrm{MPa}\end{array}$ & $\begin{array}{l}\sigma_{\text {sum C }} \\
\mathrm{MPa}\end{array}$ \\
\hline 1 & 0 & 0 & 0 & 0 & 0 & 0 & 0 & 0 \\
\hline 2 & 0.2600 & -0.2138 & 1.13785 & 0.67552 & -0.67863 & 40.439 & 39.977 & 38.623 \\
\hline 3 & 0.8990 & -0.8307 & 3.01449 & 1.65189 & -2.12937 & 75.252 & 73.889 & 70.108 \\
\hline 4 & 1.6403 & -1.7077 & 4.62600 & 2.33916 & -3.64032 & 104.383 & 102.097 & 96.117 \\
\hline 5 & 2.2306 & -2.6311 & 5.59255 & 2.58373 & -4.70361 & 128.446 & 125.437 & 118.150 \\
\hline 6 & 2.4603 & -3.3149 & 5.69812 & 2.35821 & -4.96510 & 148.103 & 144.763 & 137.439 \\
\hline 7 & 2.1852 & -3.4003 & 4.81592 & 1.72539 & -4.23850 & 163.944 & 160.853 & 154.889 \\
\hline 8 & 1.3482 & -2.4617 & 2.90244 & 0.84524 & -2.52191 & 176.487 & 174.430 & 171.063 \\
\hline 9 & $3.5527 \mathrm{E}^{-14}$ & $1.279 \mathrm{E}^{-13}$ & $9.8647 \mathrm{E}^{-15}$ & $8.7115 \mathrm{E}^{-14}$ & $-6.5379 \mathrm{E}^{-14}$ & 186.205 & 186.205 & 186.205 \\
\hline
\end{tabular}

Here of course polar inertia moments $I_{x}$ and $I_{y}$, as well as profile dangerous points coordinates $X_{\mathrm{A}}$, $Y_{\mathrm{A}}, X_{\mathrm{B}}, Y_{\mathrm{B}}, X_{\mathrm{C}}, Y_{\mathrm{C}}$ after blade load reduction, although little but change, still for the simplification of calculation the values mentioned are left unchanged.

Finally, total stresses are calculated (results to be seen in Table V):

$$
\begin{aligned}
\sigma_{\text {sum A }} & =\sigma_{\mathrm{A}}+\sigma_{c b} \\
\sigma_{\text {sum B }} & =\sigma_{\mathrm{B}}+\sigma_{c b} \\
\sigma_{\text {sum C }} & =\sigma_{\mathrm{C}}+\sigma_{c b}
\end{aligned}
$$

For more clear result overview bending $(a)$ and total $(b)$ stress $\sigma$ along the blade $r$ the following charts are build (see Fig. 4). From the charts the picture of stress distribution on the blade length is clearly seen. There is a possibility to determine percentage of the degree of curve stratification in each section. It is obvious that at the end and at the root part of the blade there is no stress and it corresponds to the blade without shroud shelf with reduced load. Low pressure turbine blades are equipped with shroud shelves (see Fig. 5). Therefore, presented below is a calculation for the version of blade with the shroud shelf.

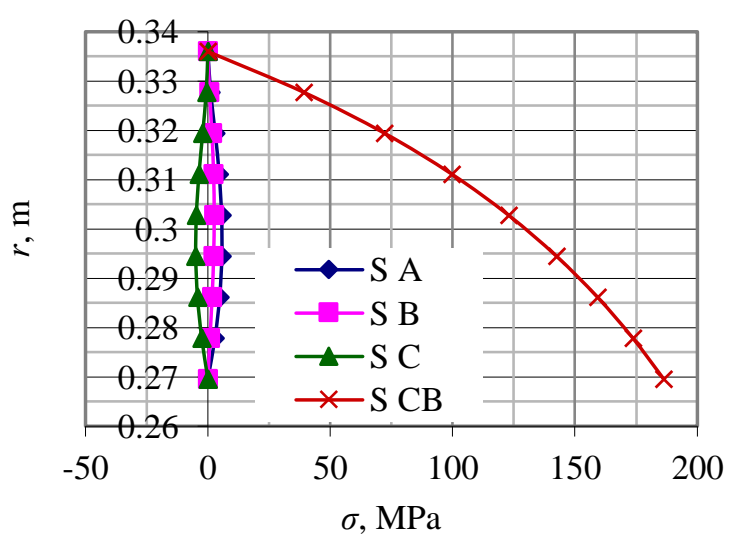

a)

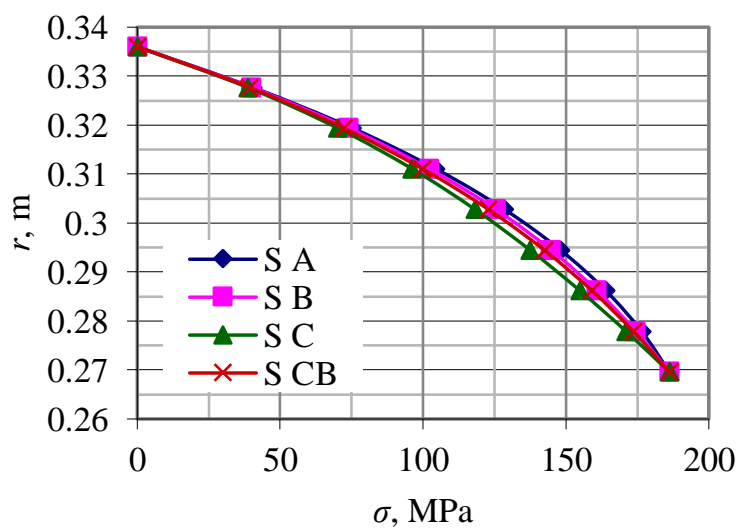

b)

Fig. 4. Bending (a) and total (b) stresses as well as tensile stress $\left(\sigma_{c f}\right)$ distribution along the blade length after stress reduction where $\sigma_{\mathrm{A}}, \sigma_{\mathrm{B}}$ and $\sigma_{C},-$ bending stresses in profile points $\mathrm{A}, \mathrm{B}$ and $\mathrm{C}$ accordingly; $\sigma_{\text {sumA }}, \sigma_{\text {sumB }}$ and $\sigma_{\text {sumC }}-$ bending and circumferential stresses in profile points $\mathrm{A}, \mathrm{B}$ and $\mathrm{C} ; \sigma_{c f}$ - circumferential force created stresses. 


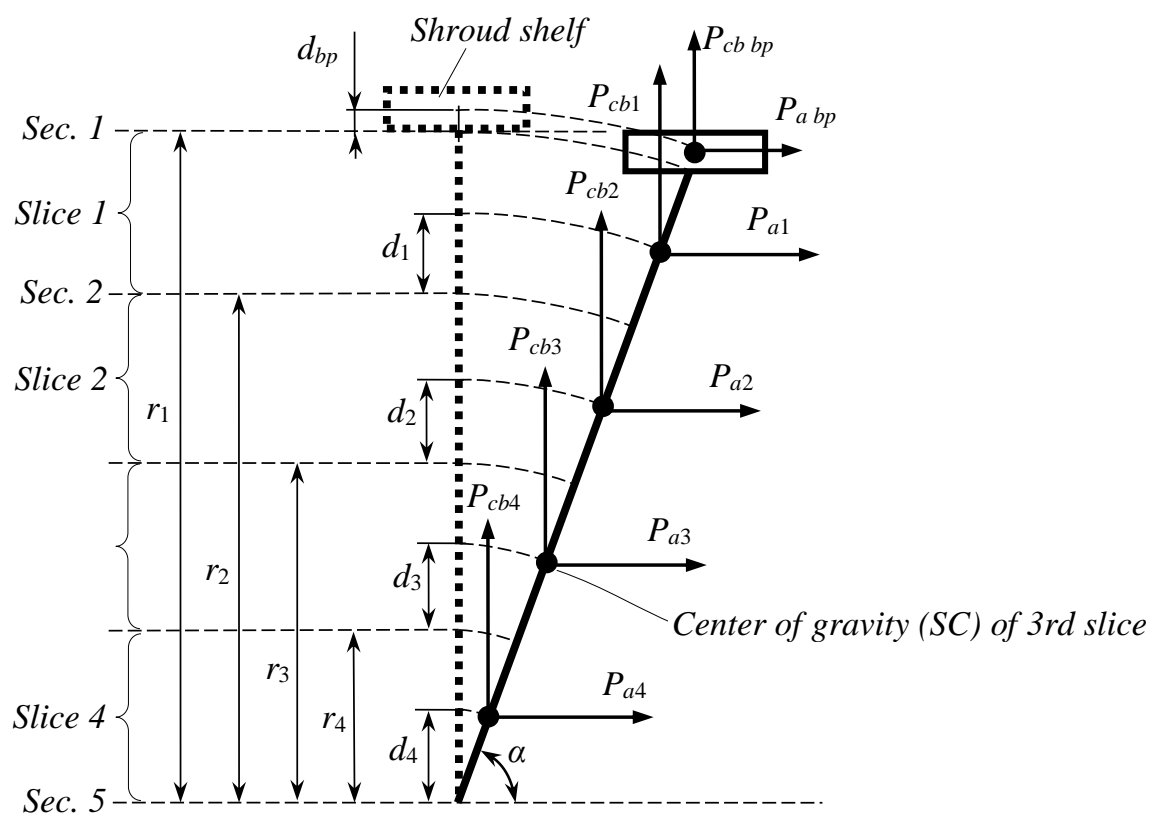

Fig. 5. Scheme of blade with shroud shelf straight and skewed position in rotor axis direction.

\section{Calculation of Profile with the Shroud Shelf}

The shroud shelf will not be calculated. As for initial data average thickness $\delta$ and width $b$ of shroud shelf are added (or shelf length in the direction of rotor axis). The calculation is analogous to the calculation of the blade without shroud shelf, this is why in the given part only the calculation phases containing the impact of shroud shelf on the blade profile are contemplated. Certainly, with the same initial data the shroud shelf will put the blade profile under bigger circumferential loads, consequently, profile geometrical measurement changes have to be made. Yet to make the analysis of the shroud shelf impact on profile easier, its measurements are left the same as for the blade without shroud shelf. Table VI shows the values analogous to table I, but those values are influenced by the shroud shelf. It can be seen that a shroud shelf increases radius for the thickness of the shelf, as if creating an additional zero section (this radius is not used in the calculations). The mass of the slice $\left(m_{\text {slice }}\right)$ in the 1 st section (or row) means the shroud shelf mass. Tensile stresses $\left(\sigma_{c f}\right)$ at the end of the blade (in the $1^{\text {st }}$ section) are created exactly by the shroud shelf.

\section{TABLE VI}

EXAMPLE OF CALCULATION RESULTS

\begin{tabular}{|c|c|c|c|c|c|c|}
\hline \multirow{2}{*}{ Section } & $r, \mathrm{~m}$ & \multirow{2}{*}{$m_{\text {slice }}, \mathrm{kg}$} & \multirow{2}{*}{$P_{c f \text { slice }}, \mathrm{N}$} & \multirow{2}{*}{$S C_{\Sigma}, \mathrm{m}$} & \multirow{2}{*}{$P_{c \varsigma \Sigma}, \mathrm{N}$} & \multirow{2}{*}{$\sigma_{c f}, \mathrm{MPa}$} \\
\hline & 0.3378 & & & & & \\
\hline 1 & 0.336 & 0.0078 & 5063.8 & 0.3369 & 5063.8 & 112.54 \\
\hline 2 & 0.3277 & 0.0032 & 2038.5 & 0.33540 & 7102.4 & 136.92 \\
\hline 3 & 0.3194 & 0.0037 & 2295.3 & 0.33240 & 9397.7 & 156.64 \\
\hline 4 & 0.3111 & 0.0043 & 2586.3 & 0.32852 & 11984.0 & 172.75 \\
\hline 5 & 0.3028 & 0.0049 & 2907.5 & 0.32405 & 14891.5 & 186.15 \\
\hline 6 & 0.2945 & 0.0057 & 3255.0 & 0.31916 & 18146.6 & 197.52 \\
\hline 7 & 0.2862 & 0.0065 & 3624.9 & 0.31395 & 21771.5 & 207.35 \\
\hline 8 & 0.2779 & 0.0074 & 4013.2 & 0.30850 & 25784.7 & 216.00 \\
\hline 9 & 0.2696 & 0.0084 & 4415.9 & 0.30287 & 30200.6 & 223.71 \\
\hline
\end{tabular}

Bending and total stress values of the blade under shroud shelf impact are shown in Table VII. 
TABLE VII

BENDING AND TOTAL STRESSES

\begin{tabular}{|l|r|r|r|r|r|r|}
\hline Section & $\sigma_{\mathrm{A}}, \mathrm{MPA}$ & $\sigma_{\mathrm{B}}, \mathrm{MPa}$ & $\sigma_{\mathrm{C}}, \mathrm{MPa}$ & $\sigma_{\text {sum A }}, \mathrm{MPa}$ & $\sigma_{\text {sum B }}, \mathrm{MPa}$ & $\sigma_{\text {sum C }}, \mathrm{MPa}$ \\
\hline 1 & 0.41 & 0.28 & -0.19 & 112.95 & 112.82 & 112.35 \\
2 & 7.43 & 4.86 & -4.67 & 144.36 & 141.79 & 132.26 \\
3 & 21.29 & 13.29 & -16.01 & 177.93 & 169.93 & 140.63 \\
4 & 39.44 & 23.49 & -33.36 & 212.20 & 196.24 & 139.39 \\
5 & 59.75 & 33.84 & -54.58 & 245.90 & 219.99 & 131.57 \\
6 & 81.39 & 43.59 & -77.97 & 278.91 & 241.11 & 119.55 \\
7 & 103.9 & 52.12 & -102.07 & 311.25 & 259.47 & 105.28 \\
8 & 126.94 & 58.80 & -125.58 & 342.94 & 274.81 & 90.42 \\
9 & 150.22 & 62.89 & -147.36 & 373.93 & 286.61 & 76.35 \\
\hline
\end{tabular}

Fig. 6 shows bending stress and total stress dependencies in the same way as it was done in Fig. 2.

The calculation of bending stress reduction of lade with shroud shelf is analogous to the calculation made for the blade without shroud shelf. Gas forces and centrifugal forces total moment equation is the following:

$$
\begin{gathered}
P_{a b p}\left(r_{1}+d_{b p}\right) \sin \alpha+P_{a 1}\left(r_{2}+d_{1}\right) \sin \alpha+P_{a 2}\left(r_{3}+d_{2}\right) \sin \alpha \\
+P_{a 3}\left(r_{4}+d_{3}\right) \sin \alpha+P_{a 4} d_{4} \sin \alpha=P_{c b b p}\left(r_{1}+d_{b p}\right) \cos \alpha+P_{c b 1}\left(r_{2}+d_{1}\right) \cos \alpha+ \\
+P_{c b 2}\left(r_{3}+d_{2}\right) \cos \alpha+P_{c b 3}\left(r_{4}+d_{3}\right) \cos \alpha+P_{c b 4} d_{4} \cos \alpha
\end{gathered}
$$

Skew angle $\alpha$ :

$$
\alpha=\tan \left(\frac{P_{c b b p}\left(r_{1}+d_{b p}\right)+P_{c b 1} \cdot\left(r_{2}+d_{1}\right)}{P_{a b p}\left(r_{1}+d_{b p}\right)+P_{a 1} \cdot\left(r_{2}+d_{1}\right)}+\frac{P_{c b 2} \cdot\left(r_{3}+d_{2}\right)+P_{c b 3} \cdot\left(r_{4}+d_{3}\right)+P_{c b 4} \cdot d_{4}}{P_{a 2} \cdot\left(r_{3}+d_{2}\right)+P_{a 3} \cdot\left(r_{4}+d_{3}\right)+P_{a 4} \cdot d_{4}}\right)
$$

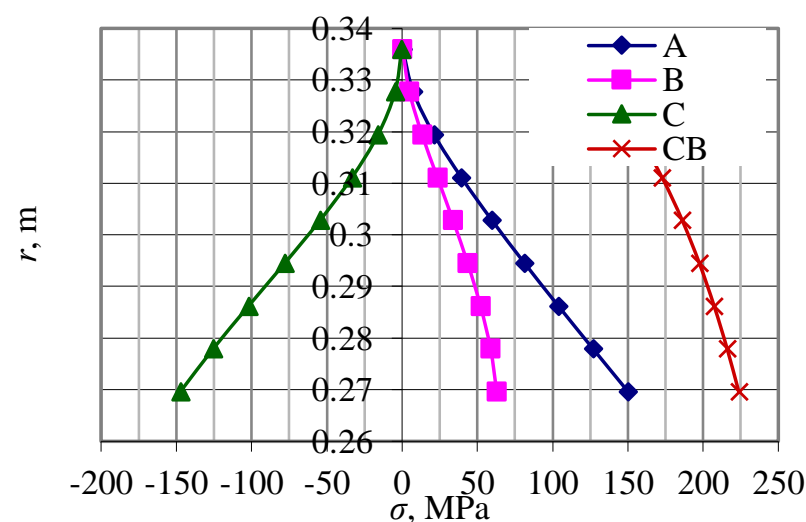

a)

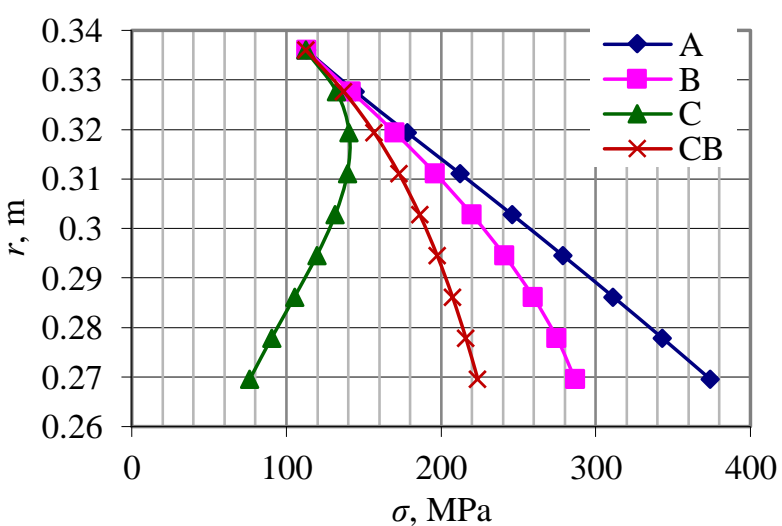

b)

Fig. 6. Bending $(a)$ and total $(b)$ stresses as well as tensile stress $\left(\sigma_{c f}\right)$ distribution along the blade length before stress reduction considering shroud shelf impact where $\sigma_{\mathrm{A}}, \sigma_{\mathrm{B}}$ and $\sigma_{\mathrm{C}}$, - bending stresses in the profile points $\mathrm{A}, \mathrm{B}$ and $\mathrm{C}$ accordingly; $\sigma_{\text {sumA }}, \sigma_{\text {sumB }}$ and $\sigma_{\text {sumC }}-$ bending and centrifugal stresses in profile points A, B and C accordingly; $\sigma_{c f}-$ circumferential force created stresses.

Table VIII shows examples of $\alpha, \cos \alpha$ and $\sin \alpha$ values in axial and circumferential directions.

TABLE VIII

\section{BLADE SKEW ANGLES}

\begin{tabular}{|l|l|l|l|l|l|}
\hline \multicolumn{2}{|l|}{ Rotor axial direction } & \multicolumn{3}{|c|}{ Rotor circumferential direction } \\
\hline$\alpha,^{\circ}$ & $\cos \alpha$ & $\sin \alpha$ & $\alpha^{\circ}{ }^{\circ}$ & $\cos \alpha$ & $\sin \alpha$ \\
\hline 86.046 & 0.0689 & 0.9976 & 86.9345 & 0.0534 & 0.9985 \\
\hline
\end{tabular}


Moment values for the blade with shroud shelf are shown in Table IX.

TABLE IX

BENDING MOMENT VALUES

\begin{tabular}{|l|r|r|r|r|}
\hline \multirow{2}{*}{ Section } & \multicolumn{2}{|l|}{ Rotor axial direction } & \multicolumn{2}{l|}{ Rotor circumferential direction } \\
\cline { 2 - 5 } & \multicolumn{1}{l|}{$M_{u}, \mathrm{Nm}$} & $M_{c f}, \mathrm{Nm}$ & $M_{a}, \mathrm{Nm}$ & $M_{c f}, \mathrm{Nm}$ \\
\hline 1 & 0.061 & 0.314 & 0.034 & 0.244 \\
2 & 1.719 & 3.781 & 1.113 & 2.933 \\
3 & 5.601 & 8.486 & 3.773 & 6.582 \\
4 & 11.652 & 14.585 & 8.069 & 11.314 \\
5 & 19.823 & 22.255 & 14.063 & 17.263 \\
6 & 30.060 & 31.686 & 21.818 & 24.578 \\
7 & 42.313 & 43.083 & 31.402 & 33.419 \\
8 & 56.529 & 56.665 & 42.889 & 43.954 \\
9 & 72.65675 & 72.65675 & 56.3585 & 56.3585 \\
\hline
\end{tabular}

It is obvious that in comparison with the blade without the shelf here the moment values grow in all sections. Bending moment $M_{x}$ and $M_{y}$ and stress values are shown in Table X. For more clear results overview the stress distribution values are presented in charts (Fig. 7).

It is evident that in case with the blade with the shroud shelf the intensity of stratification grows, which is apparently the impact of the shroud shelf itself. It can be explained by the fact that the circumferential force, and as follows, its moment, created by the shelf, is not distributed along the blade, but is concentrated at the end of the blade. It changes the force and, as follows, the moment balance along the blade. This fact also determines that the shroud shelf changes stress signs in the chosen slices. Unlike the blade without shroud shelf, the blade with the shelf has tensile stresses appearing in profile point $\mathrm{C}$ and pressure stresses in points $\mathrm{A}$ and $\mathrm{B}$. A conclusion can be made that there exists such shroud shelf mass value when stress curves stratification degree tends to 0 .

TABLE X

BENDING MOMENTS AND STRESS VALUES

\begin{tabular}{|c|c|c|c|c|c|c|c|c|}
\hline $\begin{array}{l}\text { Sec- } \\
\text { tion }\end{array}$ & $M_{x}, \mathrm{Nm}$ & $M_{y}, \mathrm{Nm}$ & $\sigma_{\mathrm{A}}, \mathrm{MPa}$ & $\sigma_{\mathrm{B}}, \mathrm{MPa}$ & $\sigma_{\mathrm{C}}, \mathrm{MPa}$ & $\begin{array}{l}\sigma_{\text {sum A }} \\
\mathrm{MPa}\end{array}$ & $\begin{array}{l}\sigma_{\text {sum B }} \\
\mathrm{MPa}\end{array}$ & $\begin{array}{l}\sigma_{\text {sum C }} \\
\mathrm{MPa}\end{array}$ \\
\hline 1 & -0.3083 & 0.1154 & -2.0416 & -1.5027 & 0.9967 & 110.500 & 111.038 & 113.538 \\
\hline 2 & -2.5490 & 1.0268 & -10.3689 & -7.3313 & 6.7941 & 126.557 & 129.595 & 143.720 \\
\hline 3 & -3.7052 & 1.5395 & -11.3077 & -7.8290 & 8.9644 & 145.333 & 148.812 & 165.605 \\
\hline 4 & -4.0161 & 1.6601 & -10.0557 & -6.9062 & 9.1079 & 162.698 & 165.848 & 181.862 \\
\hline 5 & -3.7147 & 1.4442 & -8.0105 & -5.5355 & 8.0093 & 178.144 & 180.619 & 194.164 \\
\hline 6 & -3.0136 & 0.9964 & -5.7529 & -4.0756 & 6.2200 & 191.771 & 193.448 & 203.744 \\
\hline 7 & -2.0890 & 0.4684 & -3.5798 & -2.6680 & 4.1400 & 203.777 & 204.688 & 211.497 \\
\hline 8 & -1.0654 & 0.0570 & -1.6448 & -1.3342 & 2.0279 & 214.361 & 214.671 & 218.033 \\
\hline 9 & $-2.4903 \mathrm{E}^{-20}$ & $8.527 \mathrm{E}^{-14}$ & $-2.7694 \mathrm{E}^{-14}$ & $2.95186 \mathrm{E}^{-14}$ & $-4.2925 \mathrm{E}^{-16}$ & 223.716 & 223.716 & 223.716 \\
\hline
\end{tabular}




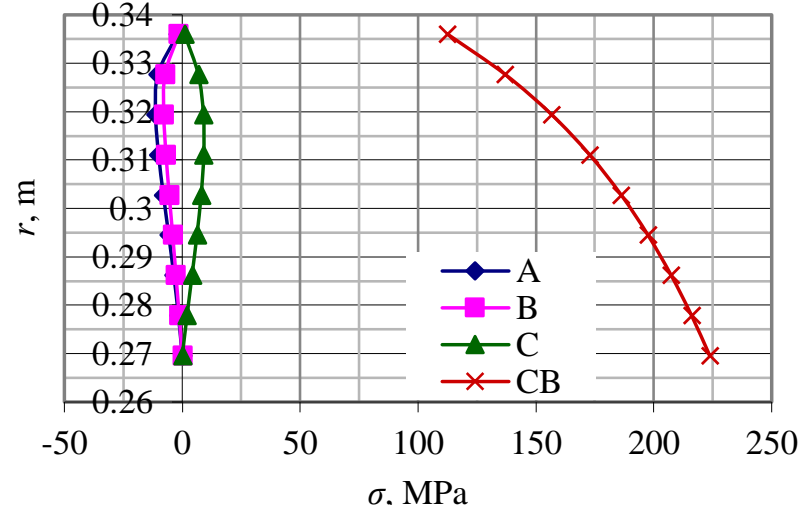

a)

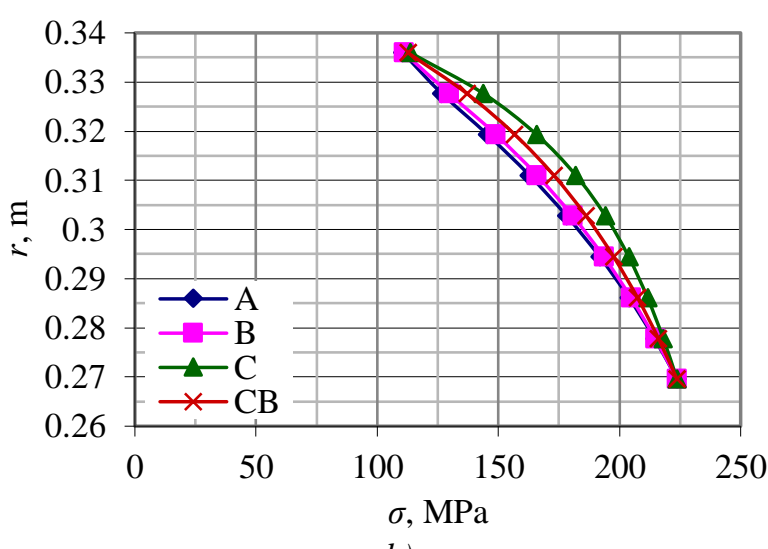

b)

Fig. 7. Bending $(a)$ and total $(b)$ stresses as well as tensile stress $\left(\sigma_{c f}\right)$ distribution along the blade length after stress reduction considering shroud shelf where $\sigma_{\mathrm{A}} \sigma_{\mathrm{B}}$ and $\sigma_{\mathrm{C}}$,- bending stresses in profile points $\mathrm{A}, \mathrm{B}$ and $\mathrm{C}$ accordingly; $\sigma_{\text {sumA }}, \sigma_{\text {sumB }}$ and $\sigma_{\text {sumC }}-$ bending and circumferential total stresses in profile points $\mathrm{A}, \mathrm{B}$ and $\mathrm{C}$ accordingly; $\sigma_{c f}-$ circumferential force created stresses.

Knowing the angles $\alpha$, the coordinates can be found in any section - distances between centres of gravity of each slice before and after skewing or so-called shoulders. Fig. 8 shows the values of those shoulders in each slice for the blades with and without shroud shelf, besides, the skewness is show separately in rotor axis and circumferential directions. As can be seen, the shroud shelf promotes the reduction of the shoulders because the shelf generally increases the mass what leads to bigger circumferential force and the moment provoked. In order not to let this moment exceed the moment provoked by gas forces, either the shoulders or the intensity of blade skew have to be reduced and that is shown in Fig. 8.
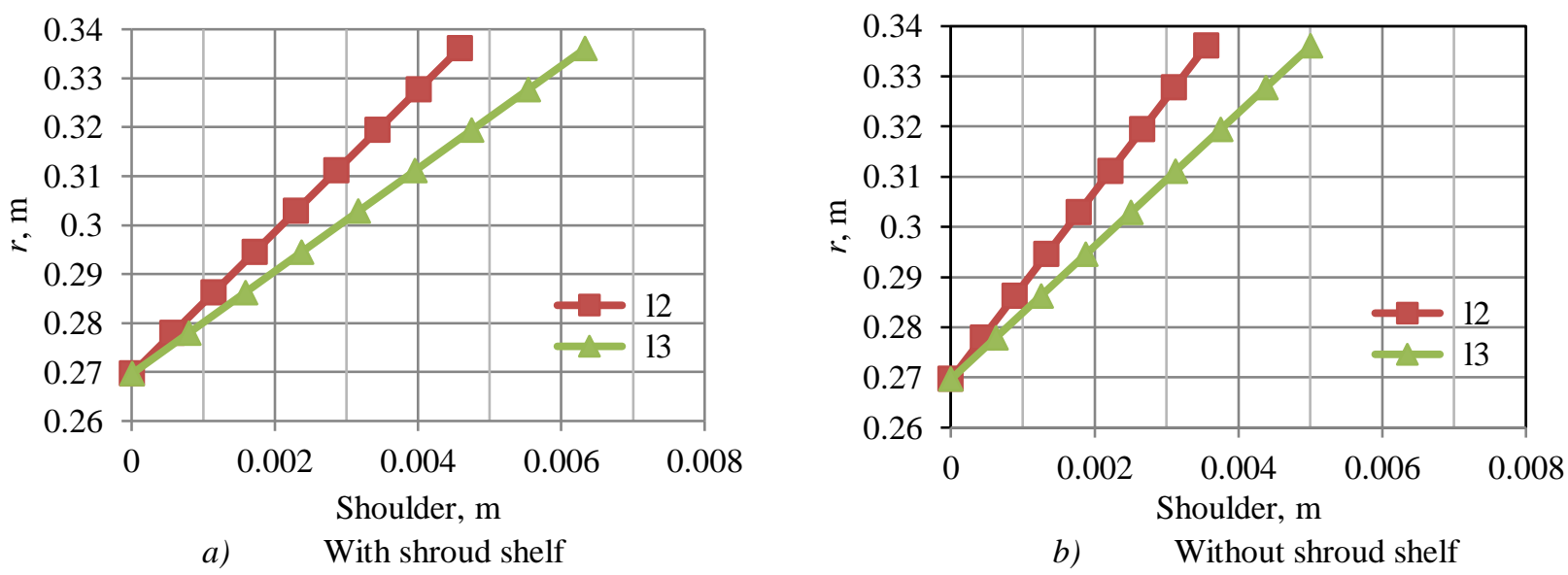

Fig. 8. Blade skewing intensities in rotor axis direction $(a)$ and circumferential direction $(b)$ performed with and without shroud shelves.

\section{RESUlts}

As a result, calculation of the profile stress distribution for the blade with and without shroud shelf was made. The calculation of the base of the profile bending stress reduction and then again profile stress distribution for the blade with reduced stresses was done as well. The method of calculation allows it easily to perform result comparison and analysis. It is possible to influence the tension condition of the blade profile only by changing the centre of mass of the shroud shelf, which is not addressed in this article. 


\section{REFERENCES}

[1] A. A. Inozemcev and V. L. Sandrackij. Gazoturbinnye dvigateli. OAO “Aviadvigatel”. Perm, 2006.

[2] V. A. Frolov, V.G. Kocenko and S. B. Luzkov. Raschet lopatok kompressora i turbiny na staticheskuju prochnost $i$ kolebanija. Samara: SGAU, 2000.

[3] M. L. Kuzmenko, V. S. Chigrin and S. E. Belova. Staticeskaja prochnost rabochih lopatok i diskov kompressorov i turbin GTD. Uchebnoe posobie. Rybinsk: RGATA, 2005.

[4] G. S. Skubacevskij. Aviacionnye gazo-turbinnye dvigateli. Konstrukcia i rascet detalej. Moscow: Mashinostroenie, 1981.

[5] I. A. Birger and R. R. Mavlutov. Soprotivlenie materialov. Moscow: Nauka, 1986.

[6] I. A. Birger, B. F. Shorr and B. Iosilevich. Raschet na prochnost detalej mashin. Moscow: Mashinostroenie, 1979.

[7] N. I. Starcev. Konstrukcia i proektirovanie AD i EU. Uchebnoe posobie. Samara: RIO SGAU, 2007.

[8] D. V. Hronina (ed.). Konstrukcia i proektirovanie aviacionnyh gazoturbinnyh dvigatelej. Moscow: Mashinostroenie, 1989.

[9] A. S. Vinogradov and G. Kartashov. Konstruirovanie lopatok i diskov AD i EU. Samara: RIO SGAU, 2007.

[10] N. I. Starcev, Konstrukcia i proektirovanie turbokompressora GTD. Uchebnoe posobie. Samara: RIO SGAU, 2006.

[11] V. P. Danilchenko, S. V. Lukachev, U. L. Kovylov, A. V. Postnikov, D. Fedorchenko, and U. I. Cybizov. Proektirovanie aviacionnyh gazoturbinnyh dvigatelej. Monografija UDK 621.431.75 Samara: SNC RAN, 2008.

[12] V. A. Zrelov, D. K. Novikov, and E. A. Panin. Formirovanie konstruktivnyh shem GTD $i$ raschet osevyh sil v turbokompressore. Uchebnoe posobie. Samara: RIO SGAU, 2006.

[13] A. I. Krukov. Nekotorye voprosy proektirovania GTD. Moscow: MAI, 1993.

[14] V. F. Haritonov. Materialy detalej aviacionnyh gazoturbinnyh dvigatelej. UFA: UGATU, 2004.

[15] V. S. Chigrin, A. I. Garkusha and A. P. Kruglikov. Raschet staticheskoj i dinamicheskoj prochnosti elementov aviacionnyh GTD. Harkov: HVVAIU, 1988.

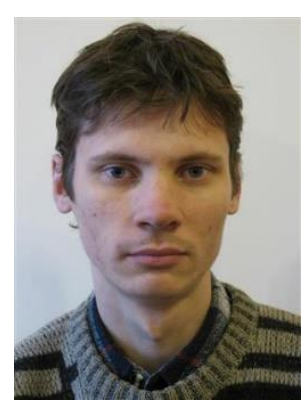

Ilmārs Ozoliṇš, Dr. sc. ing.

Education: 2000-2004: Riga Technical University, Aviation Institute, PhD in Engineering; 19982000: Riga Technical University, Aviation Institute, M. sc.; 1994-1998: Riga Aviation University, B. sc. in Engineering.

Work experience: 2005-2008: Riga Technical University Aviation institute assistant; 2008-2010: Riga Technical University Aviation institute lector; 2010-present: Riga Technical University Aviation institute doctor.

Research interests: Aviation gas turbine and piston engines, Propellers, Composite materials.

Publications: about 30 scientific and educational papers. Participation in one European projects (AISHA).

Address: Institute of Aeronautics, Faculty of Mechanical Engineering, Transport and Aeronautics, Riga Technical University, Lauvas 8. Riga, LV-1019. Latvia.

Phone: (+371) 67089990

E-mail: Ilmars.Ozolins@rtu.lv

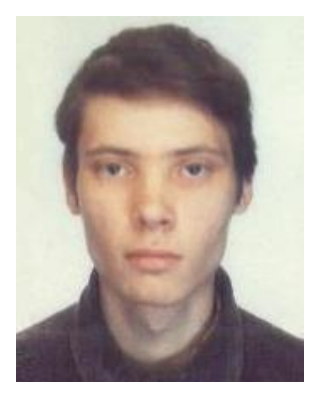

Ēriks Ozoliňš, Dr. sc. ing.

Education: 2000-2003: Riga Technical University, Aviation Institute, PhD in Engineering; 19982000: Riga Technical University, Aviation Institute, M. sc.; 1994-1998: Riga Aviation University, B. sc. in Engineering.

Work experience: 2003-2005: Riga Technical University Aviation institute assistant; 2005-2008: Riga Technical University Aviation institute lector; 2008-present: Riga Technical University Aviation institute doctor.

Research interests: acoustic emission, material strength, structural health monitoring.

Publications: about 30 scientific and educational papers. Participation in one European projects (AISHA).

Address: Institute of Aeronautics, Faculty of Mechanical Engineering, Transport and Aeronautics, Riga Technical University, Lauvas 8. Riga, LV-1019. Latvia.

Phone: (+371) 67089990

E-mail: Eriks.Ozolins@ @rtu.lv

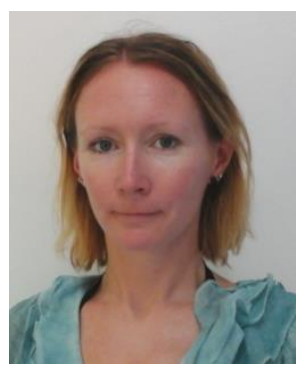

Valērija Fedotova, B. sc. ing., MA phil.

Education: 1999-2006: University of Latvia, Faculty of Modern languages, Master of Arts; 2010-2015: Riga Technical University, Institute of Aeronautics, B. sc. in Engineering.

Work experience: 2003-2005:

Flight Data Record Keeper at airBaltic, Flight attendant.

Address: Institute of Aeronautics, Faculty of Mechanical Engineering, Transport and Aeronautics,

Riga Technical University, Lauvas 8. Riga, LV-1019. Latvia.

Phone: (+371) 67089990

E-mail: volika_f@yahoo.com 